\title{
EFEITO DE SUBSTRATOS POROSOS NO ENRAIZAMENTO IN VITRO DO PORTA-ENXERTO DE MACIEIRA M-9 (MALUS PUMILLA) ${ }^{1}$
}

\author{
RENATO LUÍS VIEIRA² ${ }^{2}$ GABRIEL BERENHAUSER LEITE ${ }^{3}$, ANDERSON FERNANDO WAMSER $^{4}$
}

RESUMO - O presente trabalho foi conduzido com o objetivo de avaliar os efeitos de substratos no enraizamento in vitro do portaenxerto de macieira M-9. Foram testados três substratos: ágar, vermiculita ( $\mathrm{n}^{\circ}$ 2, granulometria média) e cinza vegetal, como suporte físico no enraizamento das miniestacas. Para os tratamento com vermiculita e cinza vegetal, meio nutritivo MS, reduzido à metade da concentração, foi adicionado em frascos de vidro de $250 \mathrm{~mL}$ contendo $15 \mathrm{~g}$ dos respectivos substratos. Brotações de $2,5 \mathrm{a} 3,0 \mathrm{~cm}$ de comprimento, com dois pares de folhas, foram transferidas para os frascos, os quais foram mantidos durante 35 dias em sala de crescimento com temperatura de $25 \pm 1,5^{\circ} \mathrm{C}$, fotoperíodo de 16 horas e intensidade luminosa de $75 \mu \mathrm{mol}^{-2} \mathrm{~m}^{-1} \mathrm{~s}^{-1}$. As maiores percentagens de enraizamento $(88,4$ e 87,9\%) foram observadas nos tratamentos com vermiculita e cinza vegetal, respectivamente. Após a avaliação do enraizamento, as plantas foram transferidas para bandejas de isopor alveoladas com 128 células e mantidas por 40 dias em casa de vegetação. A maior taxa de sobrevivência de plantas aclimatizadas $(93,5 \%)$ foi obtida com as miniestacas produzidas em meio contendo vermiculita.

Termos para indexação: micropropagação, vermiculita, pêlos absorventes, aclimatização

\section{EFFECT OF POROUS SUBSTRATES IN VITRO ROOTING OF M-9 APPLE ROOTSTOCK (Malus pumilla)}

\begin{abstract}
M9 apple rootstock. Three substrates were tested: ágar, vermiculite (number 2, medium granulometry) and vegetal ash as physical support in the rooting of the shoots. For the treatment with vermiculite and vegetal ash, MS medium nutritive, with half of the concentration, was added in glass bottles of $250 \mathrm{~mL}$ with $15 \mathrm{~g}$ of respective substrates. The shoots of 2,5 to $3,0 \mathrm{~cm}$ of length and two pair of leaves had been transferred to the bottles. After the inoculation the bottles were kept during 35 days in a growing chamber, at 25 $\pm 1^{\circ} \mathrm{C}$, for a 16 hour photoperiod with light intensity of $75 \mu \mathrm{mol} \cdot \mathrm{m}^{-2} \cdot \mathrm{s}^{-1}$. The higher percentages of rooting $(88,4$ and $87,9 \%)$ were observed for the treatments with vermiculite and vegetal ash, respectively. The number of roots per shoot was not affected by the applied treatments. After the evaluation of the rooting, the plants were transferred to a greenhouse for 40 days, in isopor alveolated containers with 128 cells. For the survival of the acclimatized plants the best treatment was vermiculite $(93,5 \%)$.
\end{abstract}

Index terms: micropropagation, vermiculite, hair roots, acclimatization

\section{INTRODUÇÃO}

O porta-enxerto tem fundamental importância na produção de mudas de frutíferas, pois este é usado para controlar o vigor da planta, bem como para oferecer resistência a patógenos e adaptação a diferentes tipos de solo. Atualmente, os programas de melhoramento para macieira concentram as pesquisas sobre porta-enxertos ananizantes, com potencial para alta produtividade, e com resistência genética às principais doenças. O porta-enxerto de macieira M-9 (Malus pumilla) é um dos mais promissores introduzidos no Brasil. Caracteriza-se por ser anão e apresentar resistência à podridão do colo causada pelo fungo Phytophthora spp., principal doença de solo em macieira (Barritt, 1995).

Os métodos de propagação in vitro são bastante eficientes na multiplicação, tanto das matrizes como dos porta-enxertos, oferecendo maior segurança no aspecto fitossanitário das mudas produzidas em comparação com os métodos convencionais. Entretanto, o enraizamento e a aclimatização são pontos críticos na micropropagação, podendo, em alguns casos, limitar esse processo. Para Collet \& Lê (1987) e Alvarez et al. (1989), a propagação clonal in vitro de espécies lenhosas é dificultada principalmente porque muitas delas não produzem raízes. Por outro lado, o genótipo da planta determina diferentes respostas nos diferentes estágios da micropropagação e/ou no enraizamento (Marks, 1991; Haissig et al., 1992). Essas respostas dependem da condição fisiológica dos explantes e das condições ambientais utilizadas (Harbage \& Stimart, 1996). A auxina possui papel central no desencadeamento hormonal da rizogênese (Margara, 1988), sendo considerado um fator primordial no processo de enraizamento de estacas de plantas lenhosas (Radmann et al., 2002). De acordo com George \& Sherrington (1984), no enraizamento in vitro, a auxina é normalmente adicionada em baixas concentrações ao meio de cultura e, apesar de variar conforme a espécie e a cultivar, as concentrações mais utilizadas situam-se entre 0,1 e 1,0 mg. $\mathrm{L}^{-1}$.

Nos meios sólidos e semi-sólidos, o ágar, um polissacarídeo extraído de algas marinhas, é o agente solidificante

(Trabalho 072-2006). Recebido em 29-06-2006. Aceito para publicação em 07-01-2007.

${ }^{2}$ Eng. Agrônomo, M.Sc., Estação Experimental de Caçador-Epagri, C.P. 591, CEP 89500-000, Caçador- SC, revieira@epagri.sc.gov.br. Autor para correspondência.

${ }^{3}$ Eng. Agrônomo, Dr., Estação Experimental de Caçador-Epagri, C.P. 591, CEP 89500-000, Caçador- SC, gabriel@epagri.sc.gov.br

${ }^{4}$ Eng. Agrônomo, M.Sc., Estação Experimental de Caçador-Epagri, C.P. 591, CEP 89500-000, Caçador- SC, afwamser@epagri.sc.gov.br 
tradicionalmente utilizado e o ingrediente mais caro do meio. Alguns autores, visando a reduzir o custo de produção, vêm testando substratos alternativos, como, por exemplo, amido de milho e de mandioca (Fortes et al., 1994) e vermiculita (Leite, 1995). Apesar de ser o agente solidificante mais utilizado, diversos autores têm citado problemas na qualidade do enraizamento. Hutchinson (1984), trabalhando com macieira, observou um pobre crescimento das raízes em ágar, apesar de apresentar mais de 90\% de iniciação radicular. Pierik (1988) afirma que as raízes formadas in vitro não se apresentam totalmente funcionais quando transferidas para in vivo, sendo fracas e com poucos pêlos absorventes, geralmente morrendo logo após. Debergh \& Maene (1981) citaram a mesma razão para a perda de crescimento das brotações enraizadas in vitro após transferidas para in vivo. Segundo eles, raízes crescidas em ágar geralmente não possuem pêlos absorventes, podendo vir a morrer logo após o transplante. Grout \& Aston (1977) observaram, em couve-flor enraizadas in vitro, uma união anormal entre a região cambial da brotação e a raiz formada, influenciando na passagem de água para as folhas. Após observarem a incapacidade de brotações de macieira de formar raízes em meio líquido estacionário e, por outro lado, apresentarem formação de raízes em meio líquido agitado, Sriskandarajah \& Mullins (1981) sugeriram que a aeração é um fator importante na formação de raízes adventícias.

A suposição de que a aeração deficiente pode vir a ser a causa da má qualidade e/ou falta de funcionalidade das raízes formadas em meio com ágar, é compartilhado por Hutchinson (1984), Simmonds (1983), Pierik (1988) e Avanzato et al.(1993). Em contrapartida, Feldman (1984) afirma que, apesar do pouco conhecimento sobre o efeito da luz na formação de raízes laterais, a luz branca poderia inibir a formação das mesmas. A presença da luz aumentaria a produção de etileno e promoveria o transporte acrópeto da auxina nas raízes, influenciando assim nos níveis destes reguladores de crescimento nos tecidos das raízes e, conseqüentemente, afetando o desenvolvimento das raízes laterais. $\mathrm{O}$ uso de substratos inertes, porosos e opacos, como a vermiculita, espumas de poliuretano (Grattapaglia \& Machado, 1990) e resíduos industriais, como a cinza vegetal, embebidos com meio nutritivo, podem ser alternativas de custo mais reduzido do que o ágar. Esses materiais, por promoverem maior aeração do meio e menor transmissão de luz, podem favorecer o enraizamento de plantas in vitro.

O objetivo deste trabalho foi avaliar a influência dos substratos vermiculita, ágar e cinza vegetal no enraizamento e na aclimatização de miniestacas de porta-enxerto de macieira M-9.

\section{MATERIAL E MÉTODOS}

Foram testados três substratos: ágar, vermiculita $\left(\mathrm{n}^{\mathrm{o}} 2\right.$, granulometria média) e cinza vegetal, como suporte físico no enraizamento de miniestacas de porta-enxertos de macieira M-9. Brotações de 2,5 a 3,0 cm de comprimento, com dois pares de folhas, foram preparadas a partir de plantas micropropagadas e repicadas cinco vezes, em intervalos de 40 dias. Para os três substratos, o meio nutritivo utilizado foi o MS (Murashige \& Skoog, 1962) reduzido à metade da concentração, suplementado com $100 \mathrm{mg} . \mathrm{L}^{-1}$ de mioinositol, $30 \mathrm{~g} . \mathrm{L}^{-1}$ de sacarose e $1 \mathrm{mg} . \mathrm{L}^{-1}$ de ácido indolacético (AIA). No tratamento-controle, o ágar foi adicionado na concentração de 6 g.L. $\mathrm{L}^{-1}$ ao meio nutritivo após a correção do $\mathrm{pH}$ e autoclavado durante 20 minutos, a $120^{\circ} \mathrm{C}$. Para os tratamento com vermiculita e cinza vegetal, o meio nutritivo foi adicionado em frascos de vidro de $250 \mathrm{~mL}$ contendo $15 \mathrm{~g}$ dos respectivos substratos e em seguida esterilizado em autoclave, similarmente ao tratamento com ágar. Durante 30 dias, os frascos foram mantidos em sala de crescimento, com temperatura de 25 $\pm 1,5^{\circ} \mathrm{C}$, fotoperíodo de 16 horas, com intensidade luminosa de 75 $\mu \mathrm{mol} . \mathrm{m}^{-2} \cdot \mathrm{s}^{-1}$. Após esse período, as plantas foram avaliadas quanto ao percentual de enraizamento, número médio de raízes, comprimento médio das raízes (medidas com paquímetro digital) e percentual de brotações enraizadas com formações de raízes secundárias.

Após a avaliação do enraizamento, as plantas foram transferidas para bandejas de isopor alveoladas (128 células), contendo $100 \mathrm{~mL}$ de substrato comercial Plantmax ${ }^{\circledR}$ por célula. As bandejas alveoladas foram mantidas em casa de vegetação, por 40 dias, sob temperatura de $25 \pm 3^{\circ} \mathrm{C}$ e recebendo a irrigação através de nebulização, controlada automaticamente para manter a umidade relativa do ambiente entre 70 e $90 \%$. Ao final desse período, as plantas foram avaliadas quanto ao percentual de sobrevivência.

O delineamento experimental utilizado foi o inteiramente casualizado, com 12 repetições e 10 miniestacas por repetição. Os resultados foram submetidos à análise de variância, sendo que os dados de percentagem foram transformados em arcoseno $\sqrt{x} / 100$, conforme Sokal e Rohlf (1995). Para a comparação de médias, foi utilizado o teste de Duncan, a $5 \%$ de probabilidade.

\section{RESULTADOS E DISCUSSÃO}

Observou-se um atraso no crescimento de raízes das miniestacas em meio com vermiculita e cinza vegetal. Aos 20 dias de incubação, as miniestacas, colocadas no meio contendo o ágar, já apresentavam raízes bem desenvolvidas, enquanto semelhante desenvolvimento de raízes das miniestacas colocadas em meio contendo vermiculita e cinza vegetal só ocorreu aos 30 dias. Esse resultado corrobora Leite et al. (2002), que detectaram atraso na formação de raízes em miniestacas de Pyrus spp em meio contendo o substrato vermiculita.

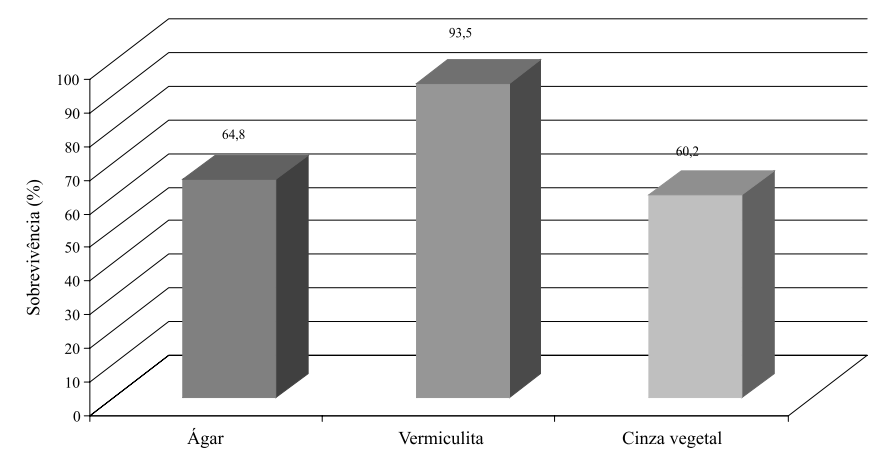

FIGURA 1 - Sobrevivência de porta-enxertos de macieira M-9 (Malus pummila) aos 40 dias após repicagem para substrato Plantimax ${ }^{\circledR}$ em estufa de aclimatização. (Caçador-SC, 2006). 
TABELA 1 - Porcentagem do enraizamento e de miniestacas enraizadas com formação de raízes secundárias, número de raízes por miniestaca e comprimento médio de raízes de miniestacas de porta-enxertos de macieira M-9 (Malus pumilla) submetidas ao enraizamento in vitro.

\begin{tabular}{|c|c|c|c|c|}
\hline Substrato & $\begin{array}{c}\text { Enraizamento* } \\
(\%)\end{array}$ & $\begin{array}{c}\mathrm{N}^{0} \text { de raízes por } \\
\text { miniestaca }\end{array}$ & $\begin{array}{c}\text { Miniestacas* } \\
\text { enraizadas com } \\
\text { formação de raízes } \\
\text { secundárias (\%) }\end{array}$ & $\begin{array}{c}\text { Comprimento médio } \\
\text { das raízes }(\mathrm{cm})\end{array}$ \\
\hline Agar & $79,1 \quad b$ & $2,3 \mathrm{a}$ & $32,6 \mathrm{~b}$ & $5,7 \mathrm{a}$ \\
\hline Vermiculita & $88,4 \mathrm{a}$ & $2,8 \mathrm{a}$ & $71,6 \mathrm{a}$ & $3,4 \mathrm{~b}$ \\
\hline Cinza vegetal & $87,9 \mathrm{a}$ & $2,1 \mathrm{a}$ & $43,7 \quad b$ & $3,9 \quad b$ \\
\hline C.V. (\%) & 11,0 & 59,8 & 40,5 & 23,1 \\
\hline
\end{tabular}

Médias seguidas de mesmas letras nas colunas não diferem entre si, pelo teste de Duncan, a 5\% de probabilidade. *Valores transformados em arco-seno $\sqrt{\mathrm{x} / 100}$.

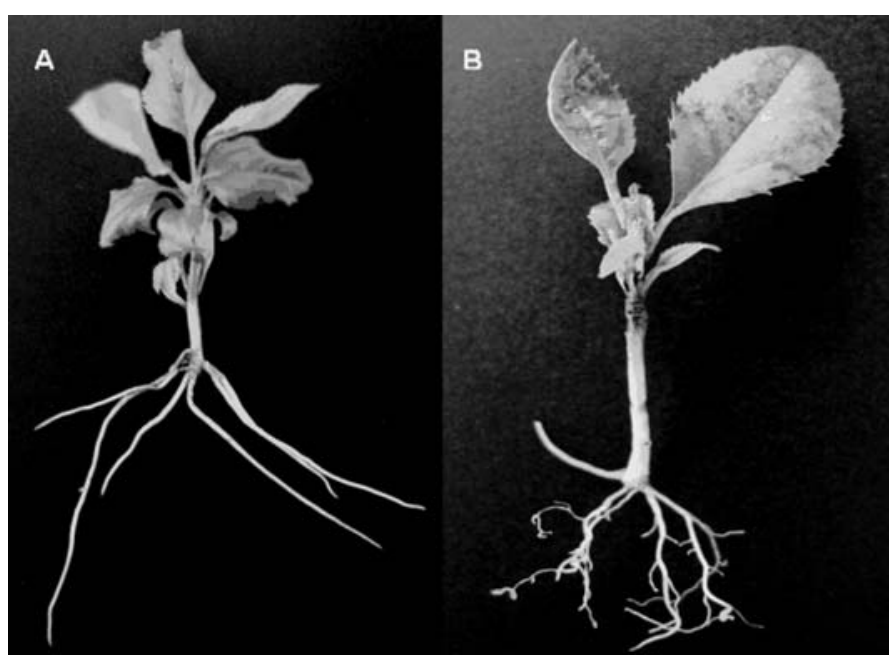

FIGURA 2 - Arquitetura do sistema radicular de plantas micropropagadas de porta-enxertos de macieira M-9 (Malus pumilla), 35 dias após o enraizamento in vitro, em: A) Ágar; B) Vermiculita. (Caçador SC, 2006)

As maiores percentagens de enraizamento (88,4 e 87,9\%) foram observadas nas miniestacas nos meios com vermiculita e cinza vegetal, respectivamente, não diferindo significativamente entre si, porém apresentando diferença significativa com as percentagens observadas no meio contendo ágar (Tabela 1).

No meio contendo a vermiculita como substrato, a percentagem de miniestacas enraizadas com formação de raízes secundárias foi de $71,6 \%$, valor significantemente superior àquele obtido nas miniestacas enraizadas em meio contendo ágar e cinza vegetal (Tabela 1). Vale ressaltar que as raízes produzidas em meio contendo vermiculita apresentaram-se mais rústicas, com ramificações e presença de pêlos absorventes (Figura 2) e que, no transplante, para aclimatização, essas características foram determinantes para a obtenção da alta taxa de sobrevivência de plantas (Figura 1). O desenvolvimento de raízes destituídas de pêlos absorventes, no meio com ágar, são ineficientes após o transplante para um substrato aerado, causando perda de vigor das plantas em casa de vegetação (Simmonds, 1983). O comprimento médio de raízes foi maior no meio contendo o ágar como substrato $(5,7 \mathrm{~cm})$, apresentando diferença significativa com os demais substratos utilizados.

As maiores percentagens de enraizamento, obtidas neste trabalho, evidenciam que a vermiculita e a cinza vegetal foram os melhores substratos para o enraizamento de porta-enxertos de macieira M-9 in vitro. Diversos autores citam a falta de aeração/ oxigenação, como o grande problema das raízes desenvolvidas em meio solidificado com ágar (Debergh \& Maene, 1981; Simmonds, 1983; Pierik, 1988; Leite, 1992). Avanzato et al.(1993) relatam que substratos com partículas finas tendem a reduzir a capacidade aeróbia com reflexos negativos na rizogênese. Além disto, a ausência de luz na base das miniestacas enraizadas, nos meios contendo vermiculita e cinza vegetal, também deve ter favorecido a indução e o crescimento das raízes.

Por outro lado, a intensidade luminosa da câmara de crescimento pode ter contribuído para inativar parte da auxina contida no meio gelatinoso utilizado neste trabalho. Fortes \& Leite (1993) e Zanol(1996) obtiveram aumento no enraizamento de estacas de macieira quando submetidas suas bases à ausência de luz. Comparando o desempenho da vermiculita e ágar, Zimmerman \& Broome (1979) citam melhores resultados com a vermiculita no enraizamento de diversas cultivares de macieira. Por outro lado, Zecca (1995), ao testar três tipos de suporte físico: ágar, vermiculita e líquido com suporte de papel, não observou diferenças significativas no percentual de enraizamento nas cultivares de marmeleiro Champion, BA-29 e maçã; já na cultivar Smyrna, o meio com ágar foi significantemente superior.

A resposta semelhante das miniestacas em meio contendo vermiculita e cinza vegetal, em comparação à resposta obtida em meio contendo ágar, quanto às variáveis percentagem de enraizamento e número de raízes por miniestaca é, neste caso, de grande significado, pois indica que é possível substituir o ágar por um desses dois substratos alternativos, sem comprometer essas variáveis. Além disso, o uso desses substratos aerados possibilitou ganhos substanciais na qualidade das raízes 
formadas, como a formação de raízes ramificadas com presença abundante de pêlos absorventes, além, é claro, do fator econômico, visto que, além do substrato de custo mais reduzido, esse tipo de raiz possibilitou uma taxa superior de sobrevivência de plantas ao final da etapa de aclimatização.

\section{CONCLUSÕES}

A vermiculita e a cinza vegetal podem substituir, com vantagens, o ágar como substrato no enraizamento in vitro do porta-enxerto de macieira M-9, apresentando um sistema radicular com qualidade superior. Essa metodologia aumenta a taxa de sobrevivência de plantas e, conseqüentemente, diminui os custos finais para produção in vitro.

\section{REFERÊNCIAS}

ALVAREZ, R.; NISSE, S.J.; SUTTER, E.R. Relationship between índole-3acetic acid levels in apple (Malus pumilla Mill) rootstocks cultured in vitro and adventitious root formation in presence of índole-3-butyric acid. Plant Physiology, Minneapolis, v.89, p.439-443, 1989.

AVANZATO, D.; CHERUBINI, S.; JAQUE, E. Potenzialitá di radicazione direta e ambientamento di microtalee di portinnesti de melo multiplicati "in vitro". Rivista di Frutticultura,Bologna, n.1, p.87-90, 1993.

BARRITT, B.H. New dwarfing rootstocks compared with standards. Good Frui Grower, Yakima, v.46, n.1, 1995.

COLLET, G.F.; LÊ, C.L. Role of auxin, during in vitro rhizogenesis of rose and apple trees. Acta Horticulturae, Wageningem, n. 212, p.273-280, 1987.

DEBERGH, P.C.; MAENE, L.J. A scheme for commercial propagation of ornamental plants by tissue culture. Scientia Horticulturae, Amsterdam, v.14, p.335-345, 1981.

FELDMAN, L.J. Regulation of root development. Plant Physiology, Minneapolis, n.35. p.223-242, 1984.

FORTES, G.R.L.; ZANOL, G.C.; CONCEIÇÃO, A.M. Uso de amido de mandioca como agente solidificante para enraizamento do porta-enxerto de macieira Marubakaido. In: CONGRESSO BRASILEIRO DEFRUTICULTURA, 2., Salvador. Resumos... p.610-611, 1994.

FORTES, G.R.L.; LEITE, G.L. Enraizamento in vitro de brotações adventícias de macieira (Malus domestica Borkh): Précondicionamento ao escuro e presença de floroglucinol. Revista Brasileira de Fisiologia Vegetal, Piracicaba, v.5, n.1, p.101, 1993.

GEORGE, E.F.; SHERRINGTON, P.D. Plant propagation by tissue culture: handbook and directory of commercial laboratories. Eversley: Exegetics, 1984. 593 p.

GRATTAPAGLIA, D.; MACHADO, M.A. Micropropagação. In: TORRES, A.C.; CALDAS, L.S. Técnicas e aplicações da cultura de tecidos de plantas, Brasília: ABCTP/EMBRAPA, CNPH, 1990.433p.

GROUT, B.; ASTON, M.J. Transplanting of cauliflower plants regenerated from meristem culture. Horticultural Research, Edinburgh, n.17, p.107, 1977.
HAISSIG, B.E.; DAVIS, T.D.; RIEMENSCHNEIDER, D.E. Researching the controls of adiventitious rooting. Physiologia Plantarum, Copenhagen, v.84, p.310-317, 1992.

HARBAGE, J F.; STIMART, D.P. Effect of pH and H-indol-3butyric acid (IBA) on rooting of apple microcuttings. Journal of the American Society for Horticultural Science, Alexandria, v.121, n.6, p.1049-1053, 1996.

HUTCHINSON, J.F. Factors affecting shoot proliferation and root initiation in organ cultures of the apple "Northern spy". Scientia Horticulturae, Amsterdam, v.22, p.347-358, 1984.

LEITE, D. Micropropagação de pereira (Pyrus spp) cultivar Carrick, 1992. 78f. Dissertação (Mestrado em Fruticultura de Clima Temperado) - Faculdade de Agronomia Eliseu Maciel, Universidade Federal de Pelotas - RS, Pelotas, 1992.

LEITE, G.B. Efeito de reguladores de crescimento, substratos, sacarose e intensidade luminosa na micropropagação de pereira (Pyrus communis L.) cv. Bartlett e do clone $\mathbf{O H} x$ F97, 1995. 50f. Dissertação (Mestrado em Fruticultura de Clima Temperado) - Faculdade de Agronomia Eliseu Maciel, Universidade Federal de Pelotas - RS, Pelotas, 1995.

LEITE, G.B.; FINARDI, N.L.; FORTES, G.R.L. Use of vermiculite as a substrate and effect of light on in vitro rooting of pears, cv. Bartlett and clone OHxF 97. Ciência e Agrotecnologia, Lavras, v.26, n.5, p.977-982, 2002.

MARKS, T.R. Rhododendron cuttings. II. Factors affecting rooting following micropropagation. Journal of Horticultural Science, Washington, v.66, n.1, p.113-118, 1991.

MARGARA, J. Multiplication vegetativa y cultivo "in vitro". Madri: Mundi-Prensa, 1988. 232p.

MURASHIGE, T.E.; SKOOG, F. A revised medium for rapid growth and bioassay with tobacco tissue cultures. Physiologia Plantarum, Copenhagen, v.15, p.473-479, 1962.

PIERIK, R.L.M. Handicaps for the large scale commercial application of micropropagation. Acta Horticulturae, Wageningem, v.230, p.63-71, 1988.

RADMANN, E.B.; FACHINELLO, J.C.; PETERS, J.A. Efeito de auxinas e condições de cultivo no enraizamento in vitro de porta-enxerto de macieira ' M-9 '. Revista Brasileira de Fruticultura, Jaboticabal - SP, v.24, n.3, p.624-628, 2002.

SIMMONDS, J. Direct rooting of micropropagated M26 apple rootstocks. Scientia Horticulturae, Amsterdam, n.21, p.233241, 1983.

SOKAL, R.R.; ROHLF, F.J. Biometry. $3^{\text {rd }}$ ed. San Francisco: Freeman and Company, 1995. 776p.

SRISKANDARAJAH, S.; MULLINS, M.G. Micropropagation of Granny Smith apple: factors affecting root formation "in vitro". Journal of Horticultural Science, Washington, v.56, n.1,p.71-76, 1981.

ZANOL, G.C. Enraizamento in vitro de porta-enxerto Marubakaido (Malus prunifolia) influenciado pela exposição de períodos de escuro, concentrações de ácido indolbutírico e floroglucinol. 1996. 92f. Dissertação (Mestrado em Fruticultura de Clima Temperado) - Faculdade de Agronomia Eliseu Maciel, Universidade Federal de Pelotas - RS, Pelotas, 1996. 
ZECCA, A.G.D. Microenxerto, enxertia de calo e enxertia de microestaca sobre calo, in vitro, como método de determinação de incompatibilidade da Pereira (Pyrus spp) sobre marmeleiro (Cydonia oblonga), 1995. $110 \mathrm{f}$. Dissertação (Mestrado em Fruticultura de Clima Temperado)

- Faculdade de Agronomia Eliseu Maciel, Universidade Federal de Pelotas - RS, Pelotas, 1995.

ZIMMERMAN, R.H.; BROOME, O.C. In vitro propagation of apple cultivars. HortScience, Alexandria, v.14, n.3, p.478, 1979. 